Herz $2019 \cdot 44: 460$

https://doi.org/10.1007/s00059-017-4673-z

Received: 27 November 2017

Accepted: 10 December 2017

Published online: 19 January 2018

(c) Springer Medizin Verlag $\mathrm{GmbH}$, ein Teil von Springer Nature 2018

CrossMark
M. Ali ${ }^{1,2} \cdot$ S. A. Lange ${ }^{1,3} \cdot$ T. Wittlinger $^{1} \cdot$ G. Lehnert ${ }^{1} \cdot$ S. Behrend ${ }^{1} \cdot$ B. Ziadeh ${ }^{1} \cdot$ K. Ali ${ }^{4}$ S. Sakellaropoulos ${ }^{2} \cdot$ G. Ganchev ${ }^{2} \cdot$ A. G. Rigopoulos ${ }^{2} \cdot$ M. Noutsias ${ }^{2}$ ' Department of Cardiology, AsklepiosHarzklinik Goslar, Goslar, Germany

${ }^{2}$ Mid-German Heart Center, Department of Internal Medicine III, Division of Cardiology, Angiology and Intensive Medical Care, University Hospital Halle, Martin-Luther-University Halle, Halle (Saale), Germany ${ }^{3}$ Medical Clinic II (Cardiology/Angiology/Intensive Care Medicine), University Heart Centre Lübeck, Lübeck, Germany

${ }^{4}$ Department of Thoracic and Cardiovascular Surgery, Klinikum Braunschweig, Braunschweig, Germany

\section{RETRACTED ARTICLE: Direct transfer of STEMI patients to cardiac catheterization laboratory}

\section{Prognostic relevance for in-hospital mortality}

\author{
Electronic supplementary \\ material \\ The online version of this article (https://doi. \\ org/10.1007/s00059-017-4673-z) contains \\ supplementary material, which is available to \\ authorized users.
}

The Editors have retracted this article because irregularities in patient numbers were identified in the paper, and therefore the conclusions may be misleading. All authors agree to this retraction. The online version of this article contains the full text of the retracted article as electronic supplementary material.

\section{Corresponding address}

\section{Ali, MD}

Mid-German Heart Center, Department of Internal Medicine III, Division of Cardiology, Angiology and Intensive Medical Care, University Hospital Halle, Martin-LutherUniversity Halle

Ernst-Grube-Straße 40, 06120 Halle (Saale), Germany dr-mali@hotmail.de muhammad.ali@uk-halle.de 